\title{
A NEW SPECIES OF GALIBLATTA FROM BRAZIL (BLATTARIA, BLABERIDAE).
}

\author{
By Louis M. Roth \\ Pioneering Research Laboratory \\ U. S. Army Natick Laboratories \\ Natick, Massachusetts oI 760
}

The genus Galiblatta Hebard includes a single species G. cribrosa Hebard, described from St. Jean du Maroni, French Guiana (Hebard, 1926). According to Bruijning (1953) the species is also common in the interior of Surinam. Princis' (1963) catalogue records only the above 2 references under Galiblatta and the genus is not included in Rocha e Silva Albuquerque's (1964) checklist of Brazilian cockroaches.

This paper contains the description of a second species of Galiblatta, closely related to G. cribrosa, which I collected near Manaus, Brazil. The original adult male and female were collected under palm frond debris on July 29, 1967, and the female gave birth on September 19, 1967. Fifteen individuals were reared and all were males ( I 4 adults, I nymph); no females were produced in this litter. The female had oviposited again by October 4, but died before giving birth again.

\section{Galiblatta williamsi new species.}

(Figs. I-3, 6-8, I2-16, 20)

Male: The number of chromosomes in the male (cells in the testes of one nymph were examined) is $2 \mathrm{n}=27$; presumably the female has $2 \mathrm{n}=28$. In addition to mitotic chromosomes (Fig. I), cells with 13 and 14 meiotic chromosomes were seen.

The male of $G$. williamsi (Fig. 2) differs from $G$. cribrosa (Fig. 4) principally in the structure of one of the left phallomeres. The phallomeres Lr (Figs. I2, I7), and R2 (Figs. I4, I6, I9) are very similar in both species. However, L2d of cribrosa (Fig. I8) is more elongate and tapered than in williamsi (Figs. I3, I5); and the apical portion of L2d is tuberculate in cribrosa (Fig. 2I) and smooth or slightly rugose (Fig. 20) (perhaps this is due to clearing and mounting the specimen on a slide) in williamsi.

Hebard (1926) in his generic description of Galiblatta stated that the styles were ". . . partially or wholly atrophied" and in G. cribrosa (Hebard, 1926, p. 237, footnote 109) the sinistral style in the male is absent ". . . apparently due to atrophy." Both styles of the male of $G$. williamsi are well developed (Fig. IO), though 


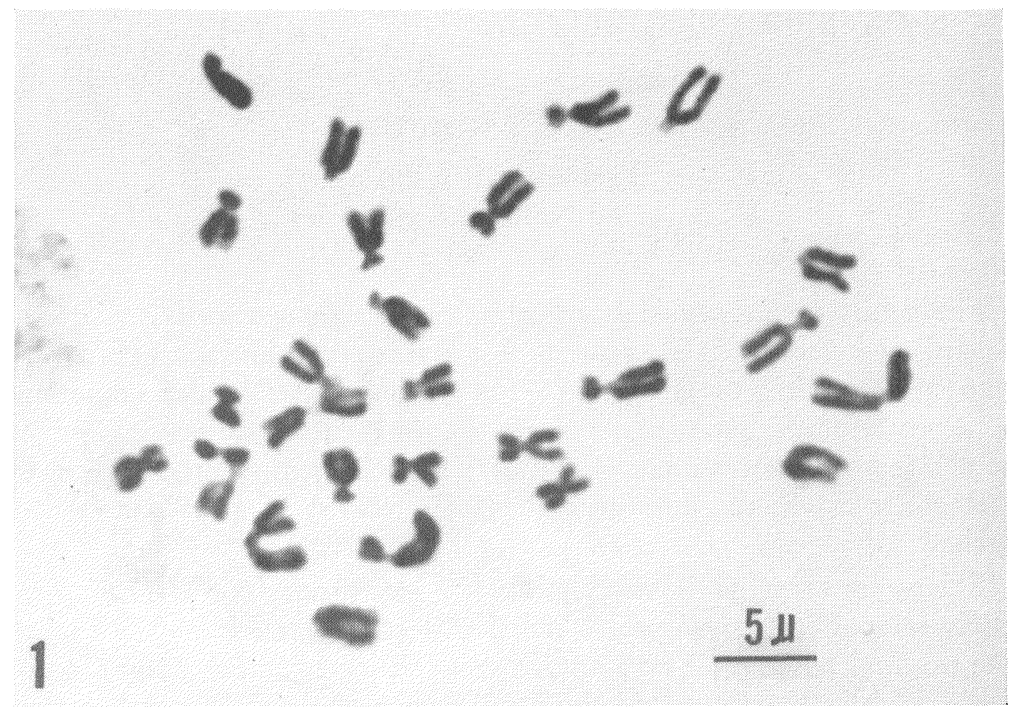

Fig. 1. Chromosomes (mitotic metaphase) from the testes of a male nymph of Galiblatta williamsi sp. nov. $(2 \mathrm{n}=27)$.

the left one is smaller than the right. It is probable that the left styles in Hebard's 2 specimens were broken off; under high magnification a small rough-edged stump represents the point of attachment of the left style in the type specimen of cribrosa (Fig. II, arrow).

The coriaceous punctulate tegmina of williamsi are shown in Fig. 6. The wings of the 2 species differ in that cribrosa (Fig. 9) has 3 complete and 2 incomplete branches of the ulnar vein, running somewhat obliquely posteriorly. In williamsi (Fig. 8) there are apparently only 2 cornplete and about 3 incomplete branches of the ulnar vein; the basal third of one of the complete branches is oblique but then runs longitudinally to the wing margin.

The adult male of williamsi is darker in tone than cribrosa. The adult males of both species of Galiblatta lack tergal glands. The male nymph (Fig. 7) shows the faint meso-lateral abdominal markings present in the female.

Female, Allotype: The most striking differences between the females of $G$. williamsi and $G$. cribrosa are found in the tegmina, and shape of the thorax. The whole anterior half (tegmina and pronotum) of cribrosa (Fig. 5) is more strongly tapered and convex 


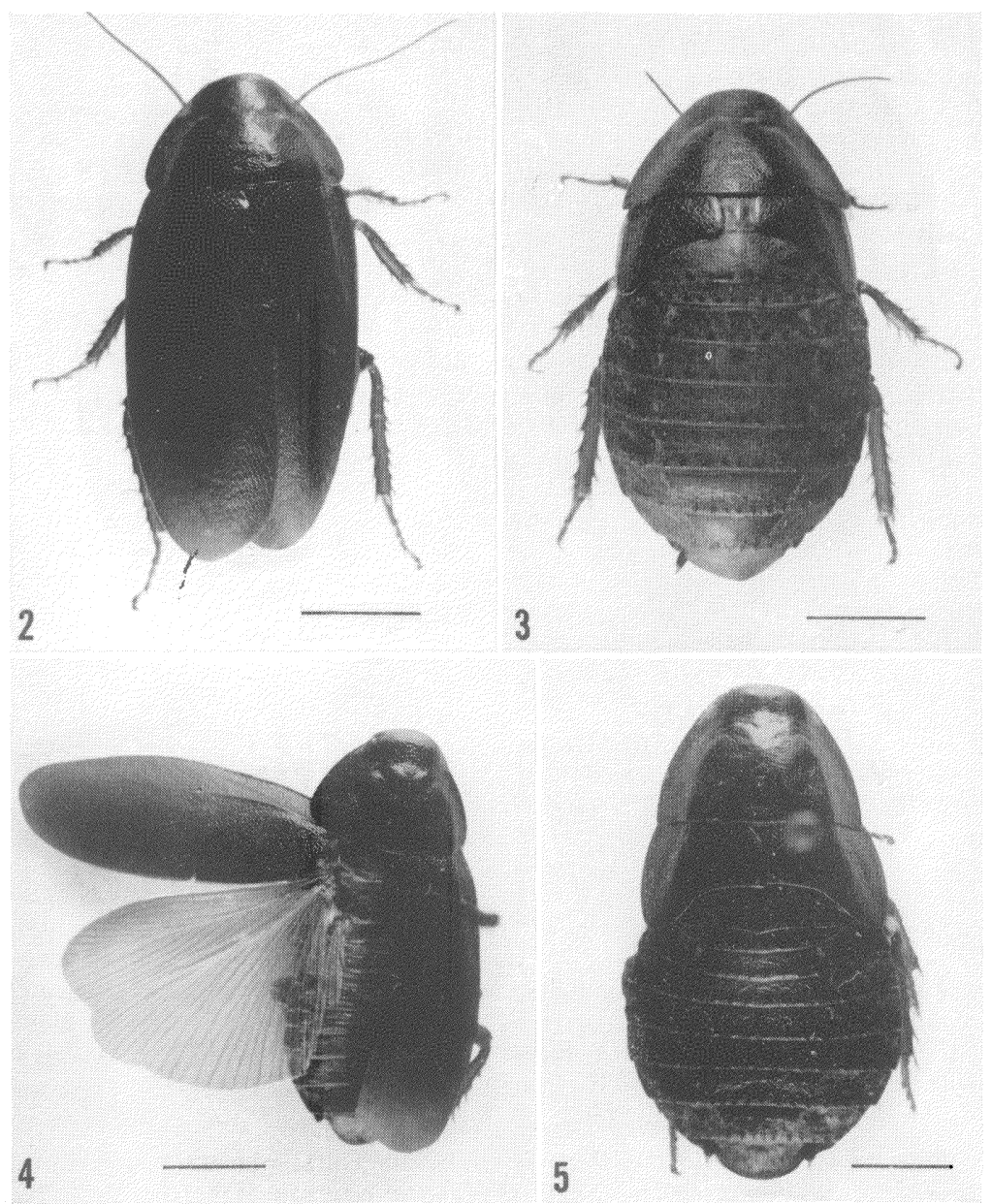

Figs. 2-3. Adults of Galiblatta williamsi sp. nov. 2. Male. 3. Female, Allotype. Taruma-Acu, Rio Negro, Amazonas, Brazil.

Figs. 4-5. Adults of Galiblatta cribrosa Hebard. 4. Male, Type (No. 1029 A.N.S.P.). 5. Female, Allotype. St. Jean du Maroni, French Guiana (Acad. Nat. Sci. Philadelphia). (Horizontal bars $=5 \mathrm{~mm}$.) 

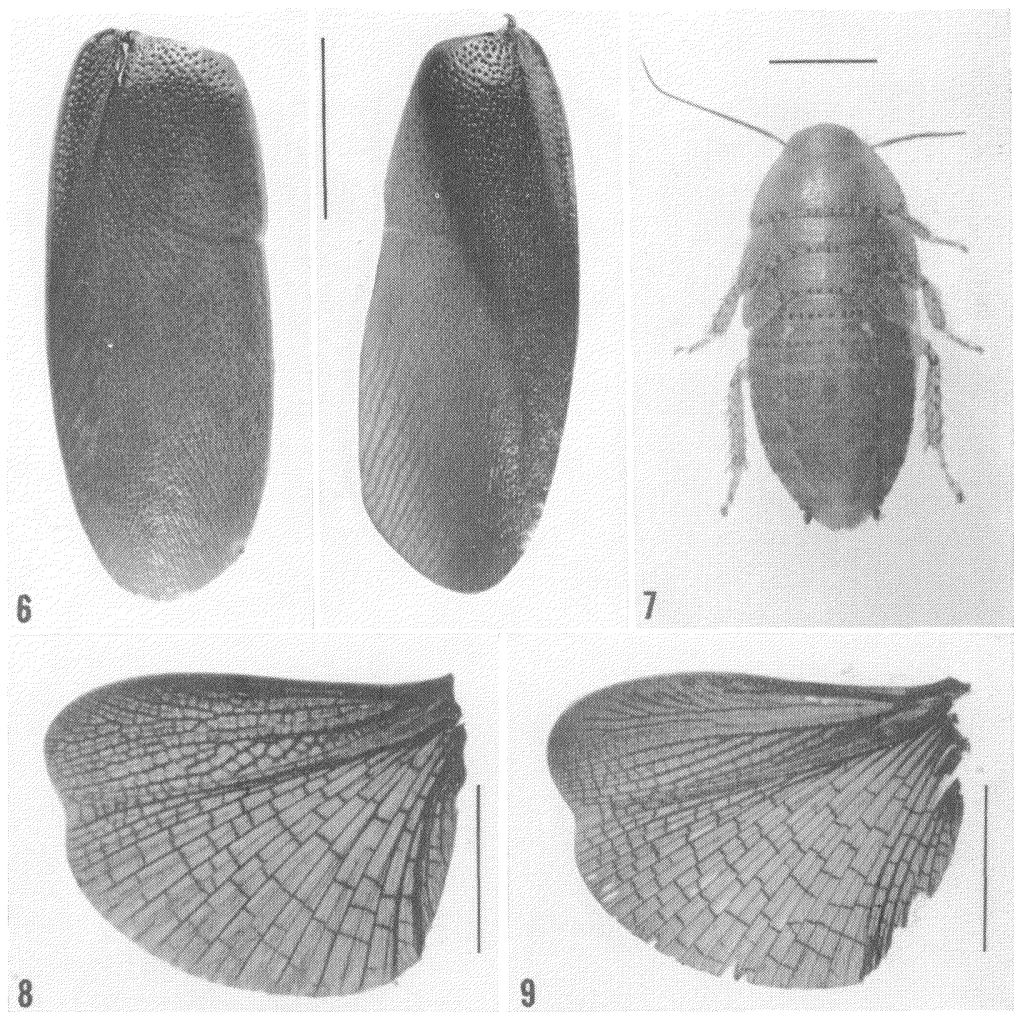

Figs. 6-8. Galiblatta williamsi sp. nov. 6. Male tegmina. 7. Full grown nymph. 8. Left male wing.

Fig. 9. Galiblatta cribrosa Hebard. Left male wing (Type No. 1029 A.N.S.P.). (Line $=5 \mathrm{~mm}$.)

Explanation of Plate 20

Figs. 10-11. Posterior portions of male subgenital plates (ventral). 10. Galiblatta williamsi sp. nov. 11. Galiblatta cribrosa Hebard (Type No. 1029 A.N.S.P.). (Both specimens are split on the left side due to flattening; arrow in Fig. 10 indicates the probable point of attachment of the left style.)

Figs. 12-21. Phallomeres of male genitalia. 12-16. Galiblatta williamsi sp. nov. 12. First sclerite of left phallomere (L1). 13, 15. Part of median sclerite (L2vm) and left dorsal sclerite (L2d). 14, 16. Hooked sclerite of right phallomere (R2). (Parts shown in Figs. 12-14 from specimen A, and those in 15 and 16 from specimen B). 17-19. Galiblatta cribrosa Hebard. Phallomeres of male genitalia (comparable to those shown in Figs. 12-14) of Type No. 1029 (Figs. 12-19 enlarged to scale shown in Fig. 18). 20-21. Enlarged apical portions of L2d. 20. Galiblatta williamsi (from Fig. 15). 21. Galiblatta cribrosa Hebard (from Fig. 18). (Terminology after McKittrick, 1964.) 


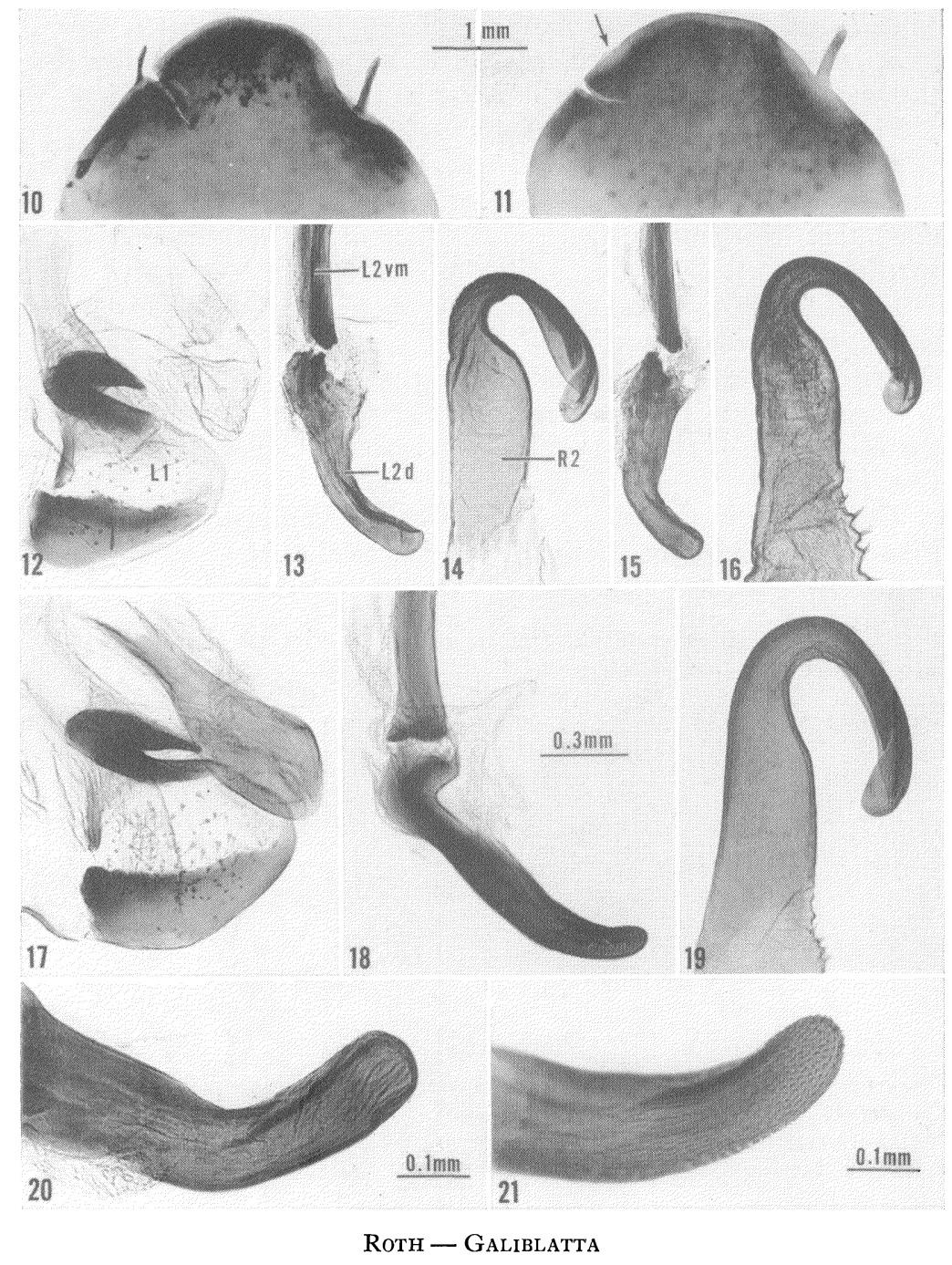


than in williamsi (Fig. 3). The tegminal pads in cribrosa are attingent and uniformly colored. The costal margins of the tegmina of williamsi are brownish yellow and the pads are distinctly separated from one another. The abdomens of both species are punctulate, but the punctulations are fine in cribrosa and coarse in williamsi.

Measurements for both species are given in Table $\mathrm{I}$.

Princis (1963) placed Galiblatta in the Laxtinae. McKittrick examined a male of $G$. williamsi and stated (personal communication) that it belongs in the Epilamprinae of her classification (McKittrick, 1964).

Type $\sigma^{7}$ (No. 70220), allotype ${ }^{\circ}, 4$ male paratypes (type and paratypes reared from the allotype \%) and one male nymph are deposited in the U. S. National Museum.

Type locality: Taruma-Açu (along a secondary river leading into the Rio Negro) about $15 \mathrm{Km}$. northeast of Manaus, Amazonas, Brazil.

The species is named after Dr. Carroll Williams, who headed Phase $\mathrm{C}$ of the Alpha Helix Expedition to the Amazon.

Table 1. Measurements (mm.) of two species of Galiblatta.

\begin{tabular}{|c|c|c|c|}
\hline \multirow{3}{*}{$\begin{array}{ll} & \\
\text { Length of body } & \hat{0} \\
& +\end{array}$} & G. cribros & Hebard $^{\mathrm{a}}$ & G. williamsi sp. nov. ${ }^{\mathrm{b}}$ \\
\hline & 20.3 ; & 19.7 & 19.5 \\
\hline & 23.9 ; & 23.1 & 21.5 \\
\hline \multirow{2}{*}{ Length of pronotum } & $5.7 ;$ & 5.8 & 5.7 \\
\hline & $7.1 ;$ & 6.7 & 5.9 \\
\hline \multirow{2}{*}{ Width of pronotum $\hat{\circ}$} & $7.8 ;$ & 7 & 7.8 \\
\hline & 9.8 ; & 9.9 & 9 \\
\hline \multirow{2}{*}{ Length of tegmen $\hat{o}$} & $15.3 ;$ & 15.3 & 14.1 \\
\hline & 5.3 ; & 4.9 & 3.8 \\
\hline \multirow{2}{*}{$\begin{array}{l}\text { Width of tegmen } \hat{\delta} \\
q\end{array}$} & & 5.9 & 6 \\
\hline & 7 ; & 6.8 & 5 \\
\hline \multirow{2}{*}{ 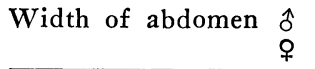 } & $8.3 ;$ & 8.6 & 8.4 \\
\hline & $13 ;$ & 12 & 10.5 \\
\hline
\end{tabular}

${ }^{a}$ Measurements of type $(\hat{\delta})$ and allotype $(q)$ are followed by those of paratypes. From Hebard (1926).

${ }^{b}$ Measurements of type ( $\left.\hat{\delta}\right)$ and allotype ( $q$ ).

${ }^{\mathrm{c}} \mathrm{Greatest}$ exposed lateral length. 


\section{Acknowledgements}

The new species was collected during Phase $\mathrm{C}$ of the Alpha Helix expedition to the Amazon in 1967. I thank the National Science Foundation for support on the Amazon expedition under Grant NSF-GB-5916, Dr. M. G. Emsley for loan of the types of Galiblatta cribrosa Hebard from the Academy of Natural Sciences of Philadelphia, Dr. Ashley Gurney for his helpful suggestions, and Mr. Samuel Cohen for making the chromosome preparation and for the photographs.

Bruijning, C. F. A.

REFERENCES

1959. The Blattidae of Surinam. Studies on the Fauna of Suriname and other Guyanas. Vol. 2: 1-103.

HeBARD, M.

1926. The Blattidae of French Guiana. Proc. Acad. Nat. Sci. Philadelphia, $78: 135-244$.

McKittrick, F. A.

1964. Evolutionary studies of cockroaches. Cornell Univ. Agr. Exp. Sta. Memoir 389, 197 pp.

Princis, K.

1963. Orthopterorum Catalogus. Pars 4: Blattariae: Subordo Polyphagoidea: Fam.: Homoeogamiidae, Euthyrrhaphidae, Latindiidae, Anacompsidae, Atticolidae, Attaphilidae. Subordo Blaberoidea: Fam. Blaberidae. 's - Gravenhage, pp. 76-172.

Rocha e Silva Albuquerque, I.

1964. Checklist dos Blattaria Brasileiros. Bol. Mus. Emilio Goeldi (n.s.) Zoologia, $41:$ 1-37. 

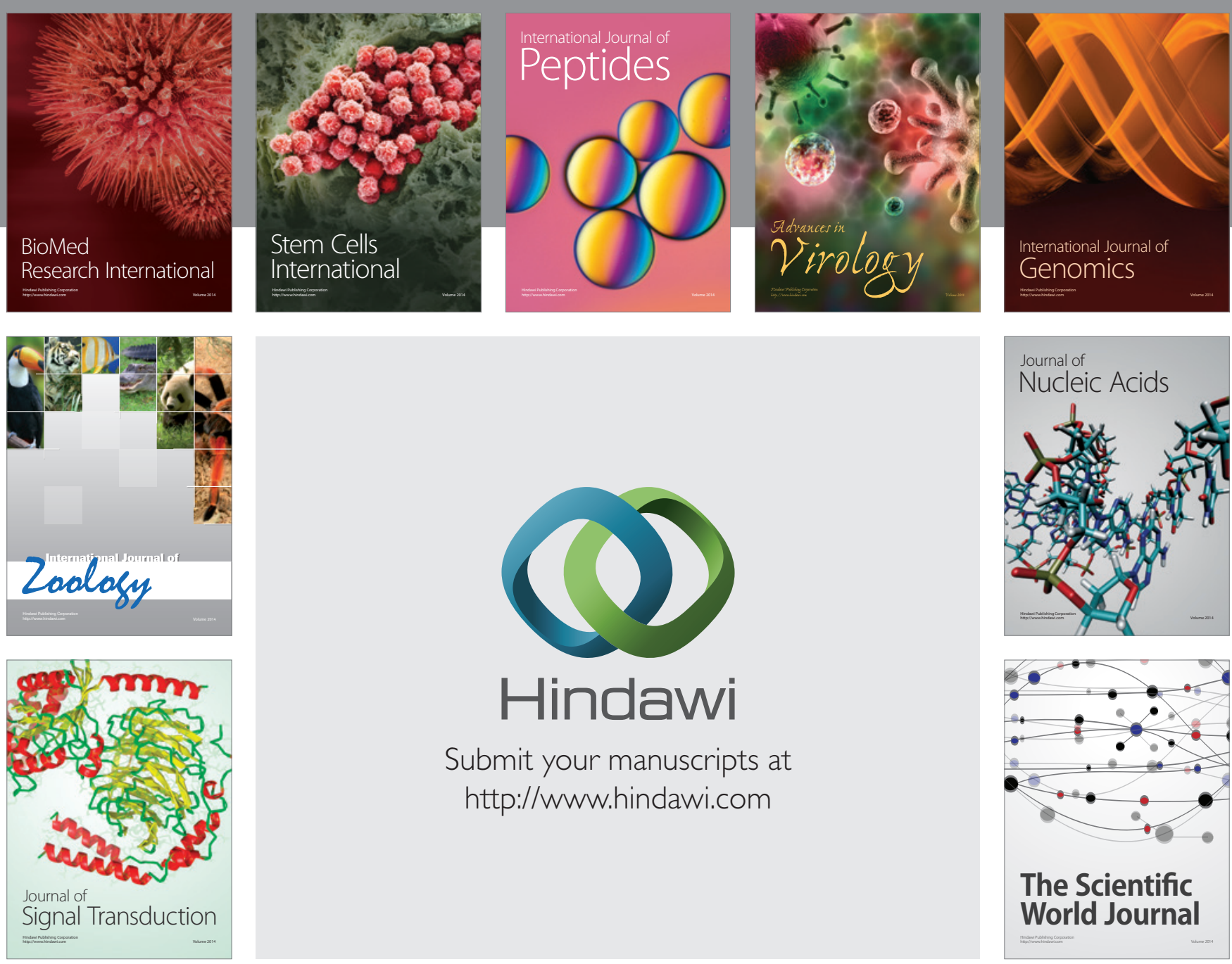

Submit your manuscripts at

http://www.hindawi.com
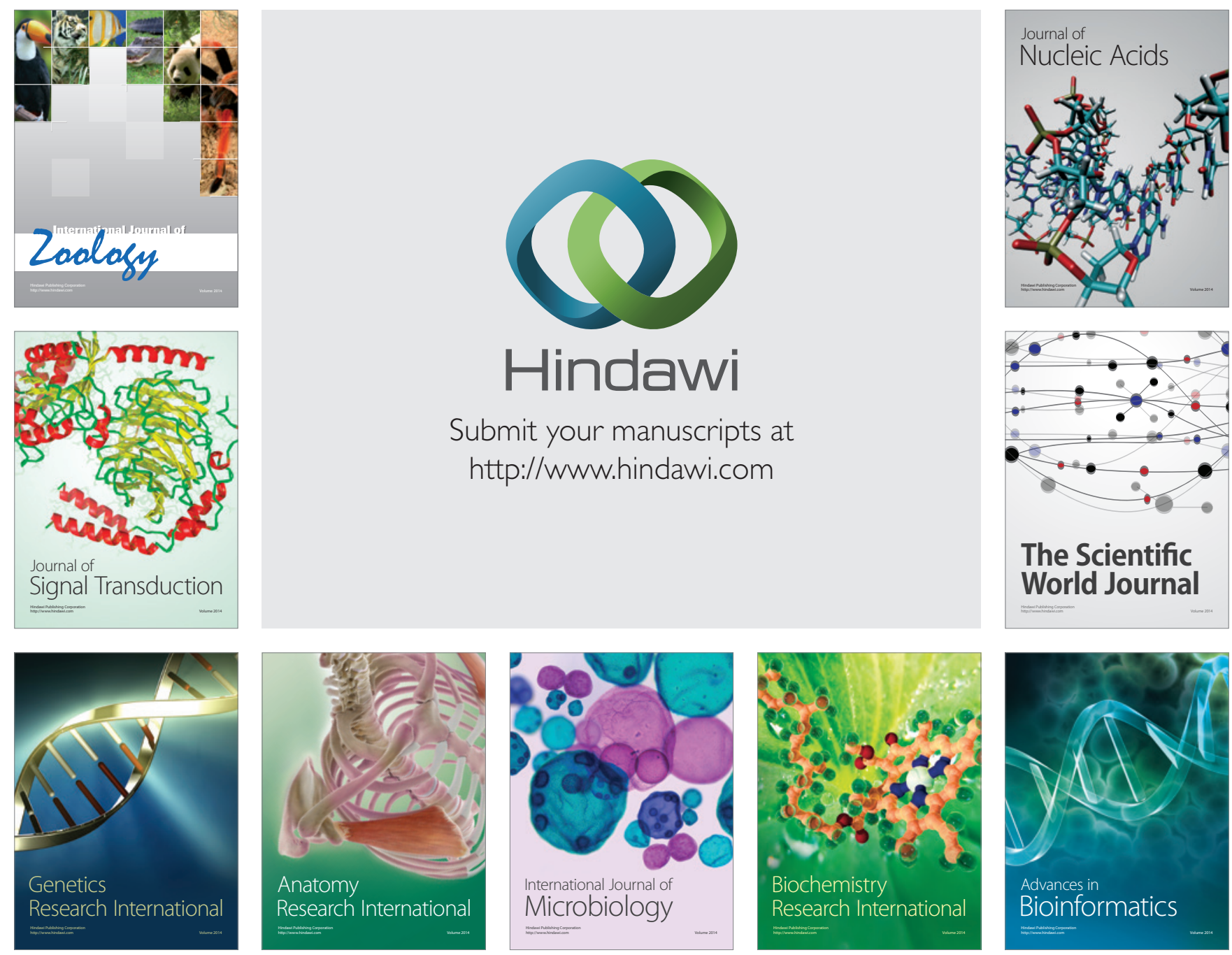

The Scientific World Journal
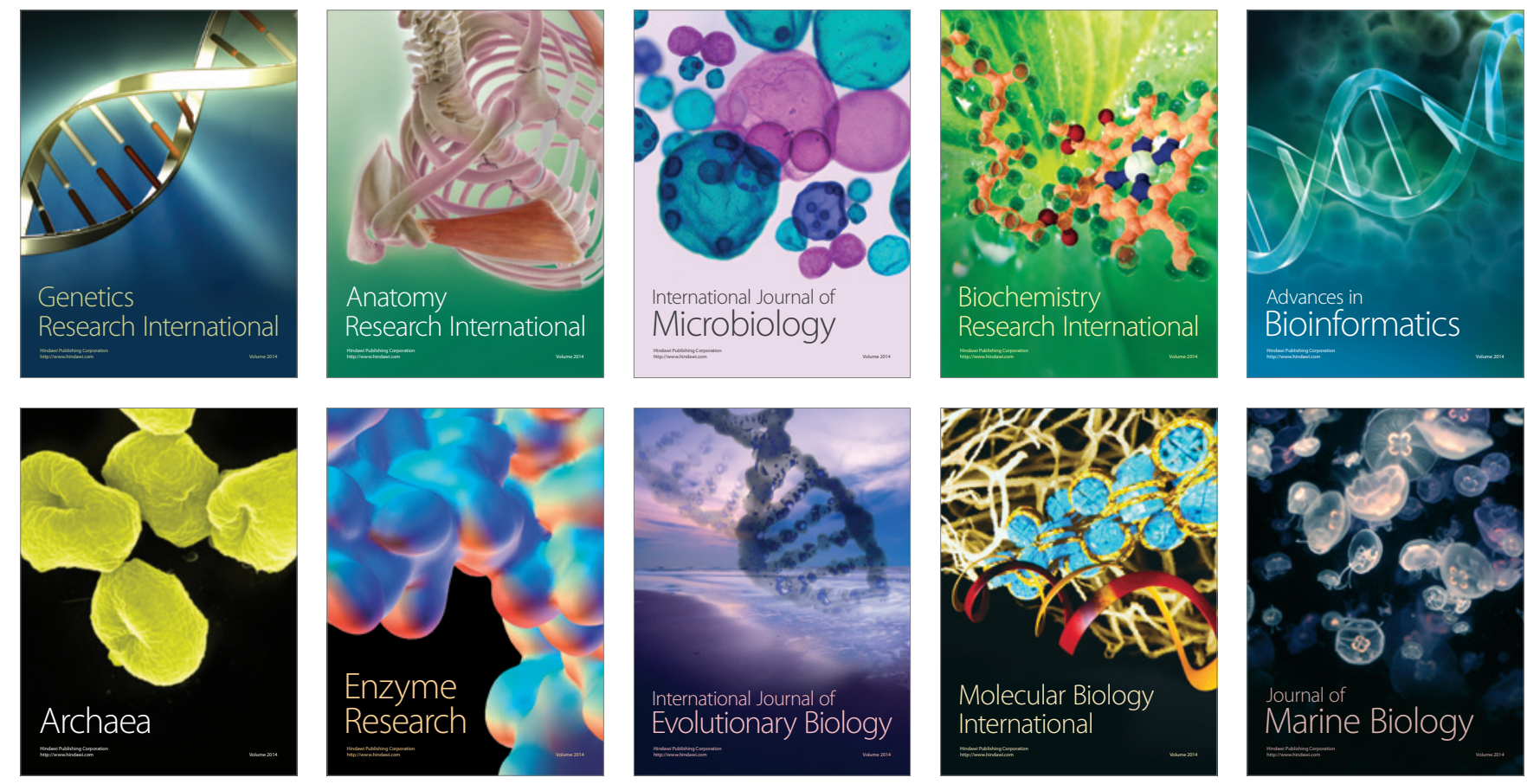